\title{
The Scale Data and Strategy Analysis of the Buildings in Jiaju Tibetan Village
}

\author{
Wei Liür, a \\ ${ }^{1}$ Architecture and Urban Planning School, Southwest University for Nationalities, \\ Chengdu, Sichuan Province, P.R.China \\ a2636026958@qq.com
}

Keywords: Jiaju Tibetan Village, The proportion of the buildings, Scale data, Ecosystem.

\begin{abstract}
By analyzing the present situation of Jiaju Tibetan Village in Sichuan Province, three issues were found, that is, a) the abrupt change of the traditional building environment; b) the unbalanced proportion of the buildings and its surroundings; c) the contradiction between numerous buildings and local ecosystem. The author separately analyzed these issues and proposed some relevant data strategies, which would be beneficial to the scientific development of the ecosystem of Jiaju Tibetan Village.
\end{abstract}

\section{Introduction}

Jiaju Tibetan Village locates in Danba County, Ganzi Tibetan Autonomous Prefecture, Sichuan Province, at an elevation of 2800 meters. There is 7000 meters away from the county and the people here are Jiarong Tibetan. The present Jiaju Tibetan Village composes of three villages. From the top of the mountain to its foot, the three villages are Village One, Village Two and Village Three (Figure 1). There are total 160 families and more than 1000 people living in these villages. The number of the families in each village is almost the same, about 50 for each. Jiaju Tibetan Village has been rated as Top Six Beautiful Countryside Towns by China National Geographic in 2005.

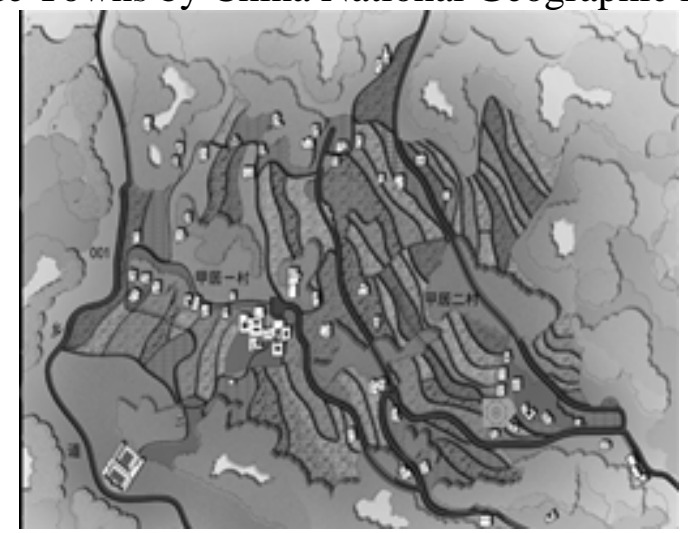

Figure 1 The planar graph of Jiaju Tibetan Village composing of three villages

\section{Analysis of the Environment Around the Buildings in Jiaju Tibetan Village}

Jiaju which refers to "one hundred families" has been Jiarong Tibetan people's living place since ancient times. They happily live here for generations with farming and herding in these mountains. Hundreds of the Tibetan buildings and watchtowers well-proportionally locate in the mountains. Some are constructed as a group while others are single, which contributes to a beautiful formation of both heavy and light density. The various trees in the mountains are pear trees, peach trees, pomegranate trees and walnut trees, etc. The harmonious balance between the buildings and natural environment reflects the local people's notion of respecting and harmoniously living with the nature.

However, during the recent decades, China's tourism industry has rapidly developed. Dozens of tourists have come to Jiaju Tibetan Village and enjoy the scenery there since 2000, which makes the village lively and change the villagers' lifestyle and living conditions. By 2004, the local government 
has been promoting Jiaju Tibetan Village as its official propaganda. They cooperate with the villagers to exploit the resources and to develop the economy. They set up an entrance and sell tickets to tourists at home and abroad. A part of the income is used to improve the infrastructure and roads in the village. Since then, the village environment has undergone great changes, not only the buildings but also the natural landscape. During the process of reconstructing, many buildings are rebuilt while some are reconstructed. After tearing down the old buildings, some families rebuild their house at the original place, which results in the poor phenomenon of completely destroying the old building. Some homeowners choose to retain these buildings and prefer to build a new Tibetan house at another place and abandon the old one (Figure 2). The old buildings would partially or entirely collapse due to long-time untended situation even if they occasionally go back. All these make the whole village incongruous even the buildings have similar outlook style.

During the reconstruction, new building materials are concrete. Stones are adopted for facade while timbers are adopted for roof. The modern materials help to repair the old buildings and keep their original repair. Some of the land is the original building materials or the demolished stone, timber of the old houses, which shows the measurement of recycling.

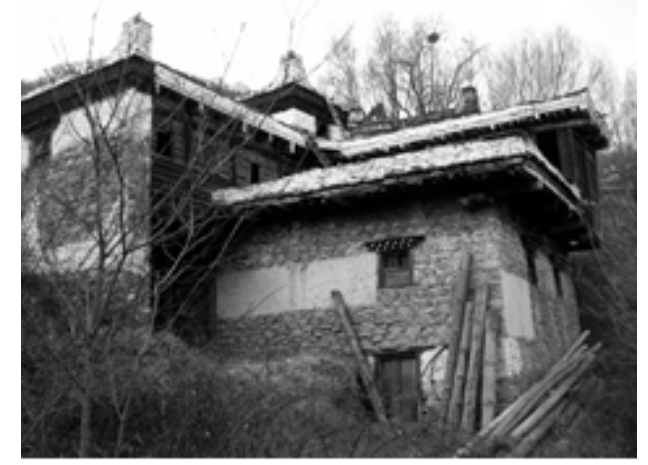

Fig. 2 An abandoned old building in Jiaju Tibetan Village

\section{The proportion of the buildings in Jiaju Tibetan Village}

Due to the economic development, the local village's functions have been changed. The public, natural, symbiotic idea has been replaced by the idea with economy, self-serving, and separation. The building, a place for generations' living, mainly relates to their privacy and religion. However, after reconstruction, the interior space is generally multiplied. For instance, Lang Tai's House in Jiaju Tibetan Village had only 160 square meters at first. To recommend more tourists, the family decided to rebuild it in April, 2006. During the renovation, the demolition materials are adopted in the new house. A three-layer building turned into a four-layer one. The building area increased to 230 square meters. And its function has also been extended. A private family home turned into a hotel. Thus, the traditional Tibetan building style has also been changed. It is no longer small and rustic and is similar to the shape of modern multi-storey buildings, which even causes a sense of harmony with the environment.

Traditional Tibetan houses and villages are "clever" and "quiet". They are inserted in dense thickets. The morphological proportion between their size, style and the construction of trees, terrain, rocky is within 0.618:1. However, the present is larger than 1:1. By comparing the values, it has formed a poignant contrast between these huge buildings and single plant and spot, which shows an inconsistent dilemma. Therefore, in perspective of harmonious beauty, it is well-known that the golden ratio is 1: 0.618 . And as the environment, its beauty lies precisely in the overall ratio of the space and each element and whether it is controlled within this value. If the number falls within it, it would form a better harmonious beauty. Similarly, the architectural landscape has damaged the harmonious beauty because its size has been changed,

The building space has increased, as well as their height, which changed a part of the landscape and its distance gradation. In the earlier ages, the buildings are small with low height. The natural landscape around the buildings can be shown from different views. However, the buildings are much 
larger and taller, which results in that the small plants and topography cannot easily be seen. Some of them has been covered, even the great white tower has never been what it was.

Building body mass increased and increased, the traditional house building towers changed the local landscape and distance level. Early time, Blockhouse building small size, high and low, its natural landscape around the roof can be revealed from different angles. And now because of construction becomes large and high, resulting in the front room of the house many small vegetation and terrain difficult to embody, is completely cover or partially covered, even if its towering Baita also seemed low without imposing it!

\section{Analysis of the Buildings' Ecological Environment in Jiaju Tibetan Village}

The large-scale village transformation makes a lot of straight and thick trees the construction accessories of the buildings. All these construction elements are original from the trees with ages around their houses. A large number of trees have been cut down to change the natural landscape, resulting in the greatly damaged local environment. In addition, bare rocks and soil are also shown in the mountains. This makes it unharmonious with the surrounding environment.

At the same time, an increase in the number of people is one of the important factors that damage the environment. According to the field survey, local villagers are unsatisfied to the ecological environment and natural landscape in Jiaju Tibetan Village and are worried with their living environment. Their understandings are mainly shown in the following table (see Appendix). Firstly, the increase of the number of tourists, leaving the waste and garbage, has directly influenced the villagers' clean life and damaged the ecological environment. Secondly, the population increasing leads to the supplying problem of drinking water, which has become a prominent contradiction. Due to more tourists, the copious water suddenly decreases and causes the lack of local villagers' domestic water. Thirdly, the discharge of sewage is also an important issue. The earlier drainage has affected on people's normal living environment. Radom emission and casual digging have both influence people's travel safety. And the odor emitted from sewage also affects the neighborhood's life around.

As shown in the above chart, the problem mainly include: peel, beverage bottles and napkins and other garbage left by the tourists are everywhere in the village. The garbage cannot be decomposed and consumed in nature, and therefore they would be drifted with the, which influences the local natural environment. Although there are workers cleaning the village, it is still difficult to collect and clean it, gradually resulting in a worse living environment. In addition, the metering facilities in the village are not in accordance with national standards, for instance, the number and the spacing ratio. According to the regulations, the sanitation resorts should be set a trash can and a ashtray within 100 meters. However, it is difficult to make it in the village. Meanwhile, the local tourism sector management is not standardized. The number of staff is insufficient and the garbage is not enough collected within time, causing these wastes are everywhere. All these problems finally make the ecological environment of Jiaju Tibetan Village much dirtier and messier than before.

Appendix:

\begin{tabular}{|c|c|c|c|c|c|}
\hline \multicolumn{6}{|c|}{ Questionnaire } \\
\hline Interviewees & $\begin{array}{l}\text { The } \\
\text { pollution of } \\
\text { rubbish }\end{array}$ & $\begin{array}{c}\text { The lack of } \\
\text { domestic water }\end{array}$ & $\begin{array}{c}\text { The } \\
\text { discharge of } \\
\text { sewage }\end{array}$ & $\begin{array}{c}\text { The environment } \\
\text { damage around the } \\
\text { buildings }\end{array}$ & $\begin{array}{c}\text { The relation } \\
\text { between } \\
\text { neighbors }\end{array}$ \\
\hline Villagers (60) & 56 & 60 & 53 & 35 & 27 \\
\hline Workers (10) & 9 & 10 & 7 & 6 & 8 \\
\hline Visitors (30) & 21 & 11 & 19 & 26 & 5 \\
\hline
\end{tabular}




\section{Strategy Analysis of the Building Scale of Jiaju Tibetan Village Dominated by Ecological Environment}

Analysis of the scale data of the buildings, people and environment. People live in the buildings. The buildings are located in a specific place and environment. The development of environment, including society, economy and culture, constitutes a dynamic ecological environment. As individuals, people have not too much change in their height, as well as their body, either in the past or at present. Their height is still almost within $1.5 \mathrm{~m}$ to $1.8 \mathrm{~m}$. The ancient humans are usually around $1.6 \mathrm{~m}$. According to historical records, the ancient Chinese people are shorter than the modern people. In the ancient times, the standard unit of length is "chi", and the length is slightly different in different dynasties. The earlier the dynasty it is, the shorter the unit length is. In Qin Dynasty, a unit length equals to 0.23 meters, but in Ming and Qing Dynasty, it equals to 0.33 meters. The ancient saying, "a seven-chi man", is basically a statement of Han Dynasty, whose unit length is consistent with Qin Dynasty. Seven chi equals $1.61 \mathrm{~m}\left(7^{*} 0.23 \mathrm{~m}\right)$. Therefore, it can be estimated that the ancient people are generally $1.60 \mathrm{~m}$. Obviously, the function of traditional ancient architecture is only to provide the family a place for housing, living and production purposes. Therefore, its height is almost $1.61 \mathrm{~m}$, in order to meet the people's daily requirement. The height of each layer of the new buildings is $3.0 \mathrm{~m}$. The total height of three layers is $10.0 \mathrm{~m}$. During the field research (Figure 2), some of the buildings that have not been fully renovated have the right size.

A building depends on people's height and its own features. These buildings have the height of $10.0 \mathrm{~m}$, three layers and an area of 160 square meters. The people's height and the tall trees form a obvious comparison and make it harmonious with the environment, which shows the best proportion between buildings and environment. Now, the buildings have more and more functions. And the building space also becomes larger, which causes the unharmonious proportion between buildings and people and the contradiction between buildings and natural environment. This mainly reflects the fact that the present buildings generally pursuit economic and personal interests, instead of the environment and place. After reconstructing, although the buildings still own their historic reputation, they lost their traditional functions. Now, they are multilayer houses. The original buildings generally have three or four layers, while the new may even have seven layers, becoming them hotels or shops. The people widen their houses, as well as lengthen them, which makes the buildings completely lose the original proportion. The new ones only keep the external appearance, the shape, the color, which is greatly awkward.

The traditional proportion of the buildings in Jiaju Tibetan Village. The renovation should comply with the original proportion between building space and people, as well as the proportion between building space and environment. The renovation should also keep the original style and size. The single layer height should fall in $2.8 \mathrm{~m}$ to $3.5 \mathrm{~m}$; the bay should be $12 \mathrm{~m}$; the depth should be $15 \mathrm{~m}$; the total height should be within $15 \mathrm{~mm}$; the number of total layers should be three to five. Traditional building materials are still adopted for construction. Modern reinforced concrete materials are also mainly used. Its outside is pieces of rock paste, in order to maintain the similarity of the traditional materials, especially the sense of color and natural sense. For the economic factors, the villagers could build some new houses around the old ones in order to meet the requirement of more passengers. This can also keep the original style and size. If the subordination relation has been paid much attention between two old buildings even more, the proportion would be more harmonious.

\section{Conclusions}

Jiaju Tibetan Village is one of the most beautiful and natural villages in Ethnic Areas. Its beauteous natural scenery and architectural forms contribute to its ecological and harmonious elements. Therefore, it is extremely important to protect the buildings. It is necessary to understand its development status, analyze its construction environment and find out the main problems and solving strategies. This is beneficial to the development of local ecological construction, as well as to the 
sustainable heritage of the traditional building scales and modulus, which keeps the balance of buildings, people and the environment. That is the right purpose of this paper.

\section{Acknowledgement}

Funding: General project on natural science for central universities in 2015 (Project No.: 2015NYB02); The design assessment of Tibetan herdsmen's new houses in Sichuan Province in perspective of environmental behavior, a project of the Research Center for Minorities in Southwestern China, the key research base on humanities and social sciences of State Ethnic Affairs Commission (Project No.: 2013009).

\section{References}

[1] Y.G. Peng. Creativity and Display. Harbin: Heilongjiang Science and Technology Press,1994.

[2] Liu Wang \& SUN Lu, et al. The problem of the tragedy of public lands in the tourism development of minority villages and its Strategies. Research on Development, 2008, (1): 125-129.

[3] Pan Heming, et al. The Tibetan Dwellings in the West of Sichuan Province . Housing Science, 1991, (9): 40-41.

[4] Liu Wei \& Liu Chunyan, et al. Thinking of the Beauty and Virtue of the Facilities in Qingdao World Horticultural Exposition. $20142^{\text {nd }}$ International Conference on Economic, Business Management and Education Innovation , 2014, 37:120-124.

[5] Liu Wei. A Research on the Construction of Beita, Zhongjiang County. Sichuan Cultural Relics, 2015, (1):70-74. 